DOI 10. 18307/2021. 0614

(c) 2021 by Journal of Lake Sciences

\title{
洱海沉水植物群落恢复与优化初探”
}

\author{
杨 桐 ${ }^{1}$, 袁昌波 ${ }^{2 * *}$, 曹 特 $^{2}$, 文紫豪 ${ }^{2}$, 丑庆川 ${ }^{2}$, 毛永杨 $^{3}$, 张霄林 $^{2}$, 倪乐意 $^{2}$ \\ (1:云南省大理市洱海管理局,大理 671000) \\ (2: 中国科学院水生生物研究所,武汉 430072) \\ (3:云南省大理州食品检验检测院,大理 671000)
}

\begin{abstract}
摘 要: 近几十年来, 在人湖营养盐增加, 水质持续下降, 藻类生物量逐年升高及水位大幅波动下, 洱海沉水植物群落演 替速度加剧. 2016 年 7 月调查显示: 洱海沉水植被退化严重, 物种数量显著低于近期 (2011 年) 历史水平, 分布面积较有 记录的历史最高水平 (1980s) 下降超过 70\%, 优势物种由 $1960 \mathrm{~s}$ 的海菜花 (Ottelia acuminata)、蓠齿眼子菜 ( Stuckenia pecti$n a t a)$ 和大茨藻 (Najas marina) 等转变为微齿眼子菜 (Potamogeton maackianus)、金鱼藻 (Ceratophyllum demersum) 以及苦草 (Vallisneria natans). 沉水植物群落在浅水区 $(0 \sim 2.5 \mathrm{~m})$ 主要遭受了浮叶植物细果野菱 (Trapa maximowiezii) 过度生长带来 的生境胁迫, 在中等水深区 $(2.5 \sim 4 \mathrm{~m})$ 面临微齿眼子菜和金鱼藻的过度生长导致的群落结构的单一化影响, 而在深水区 $(>4 \mathrm{~m})$ 面临着面积菱缩的风险, 这些严重抑制了沉水植物清水稳态效应的发挥. 通过对比洱海典型湖湾洱滨村水域沉水 植物群落结构在恢复与优化前后的变化, 发现洱滨村水域各水深区间沉水植物群落各项多样性指标与恢复物种的丰度 均显著提升. 因此, 我们总结提出了针对洱海典型富营养湖湾沉水植被恢复和管理的建议和对策, 以期为后续进一步开 展洱海生态系统恢复相关工作提供依据.
\end{abstract}

关键词: 洱海;沉水植被;现状; 恢复;优化

\section{Preliminary study on recovery and optimization of submerged macrophyte community in Lake Erhai, China*}

Yang Tong ${ }^{1}$, Yuan Changbo ${ }^{2 * *}$, Cao $\mathrm{Te}^{2}$, Wen Zihao ${ }^{2}$, Chou Qingchuan ${ }^{2}$, Mao Yongyang ${ }^{3}$, Zhang Xiaolin ${ }^{2} \&$ Ni Leyi ${ }^{2}$

(1: Dali Erhai Lake Administration, Yunnan Province, Dali 671000, P.R.China)

(2: Institute of Hydrobiology, Chinese Academy of Sciences, Wuhan 430072, P.R. China)

(3: Food Inspection and Testing Institute of Dali, Yunnan Province, Dali 671000, P.R.China)

Abstract: With the increasing exogenous nutrients, the continued declining water quality, the year-to-year increasing algae biomass, and the sharply fluctuating water levels, the succession rate of the submerged macrophyte community in Lake Erhai increases over the past several decades. The survey in July 2016 showed that the submerged macrophyte community in Lake Erhai was seriously degraded, the number of species was significantly lower than recent (2011) historical level, and the distribution area fell by more than 70\% from the historical high, and the dominant species were transformed from Ottelia acuminata, Stuckenia pectinata and Najas marina (1960s) to Ceratophyllum demersum, Potamogeton maackianus and Vallisneria natans. Submerged macrophytes mainly suffered from the stress caused by Trapa maximowiezii in shallow waters $(0-2.5 \mathrm{~m})$, and faced the simplification of the community structure caused by the overgrowth of $C$. demersum and $P$. maackianus in the area with medium water depth ( $2.5-4$ $\mathrm{m}$ ), and subjected to area shrinkage in deep waters $(>4 \mathrm{~m})$, which severely inhibited its positive ecological functions. By comparing the structures of submerged macrophyte community before and after the implementation of the submerged vegetation restoration and management project in the waters of Erbin Village, a typical bay in Lake Erhai, we found that artificial restoration and optimi-

* 2021-03-04 收稿; 2021-04-12 收修改稿.

2018 年度洱海水生植被恢复与管理项目 (云南省大理州政府委托) 资助.

** 通信作者; E-mail: yuancb@ihb.ac.cn. 
zation measures positively improved the submerged plant communities in various areas with different water depths in Erbin Village. The abundance of restored species and the diversity indicators of the community was significantly improved. Therefore, we put forward suggestions and countermeasures for the restoration and optimal management of submerged vegetation in the typical eutrophic lake bays of Lake Erhai, with a view to provide a basis for the follow-up projects of the ecosystem restoration in Lake Erhai.

Keywords: Lake Erhai; submerged vegetation; current situation; restoration; optimization

洱海地处云贵高原, 是大理市境内最大的淡水湖泊, 也是云南省第二大淡水湖泊, 是大理市农业、生产 与生活用水的主要来源 ${ }^{[1]}$. 随着近几十年来大理市经济和社会发展, 人类活动对洱海生态系统服务功能产 生强烈负面效应, 其中作为湖泊生态系统初级生产者的水生植物, 尤其是沉水植物的响应尤为明显 ${ }^{[2-3]}$.

自 1980s 至今, 洱海沉水植物物种数量明显减少. 厉恩华等 ${ }^{[2]}$ 于 2009 年 5-12 月间, 先后对洱海水生植 物进行了 3 次调查, 发现洱海分布有沉水植物 26 种, 眼子菜、角果藻和蓖齿眼子菜等已消失, 沉水植被覆盖 面积约为湖面的 $8 \%$. 符辉等 ${ }^{[3]}$ 在查阅大量资料的基础上, 发现洱海沉水植物群落分布面积和最大水深均呈 现明显的下降趋势, 洱海沉水植物生物量从 $60 \times 10^{4} \mathrm{t}(1970 \mathrm{~s}-1990 \mathrm{~s})$ 减至 $20 \times 10^{4} \mathrm{t}$ (2010 年), 分布面积 由全湖面积的 40\% (1970s - 1990s) 下降至 10\%左右(2003 年), 分布的最大水深由 $6 \sim 10 \mathrm{~m}(1970 \mathrm{~s}$ ) 下降至 $1990 \mathrm{~s}$ 的 $6 \mathrm{~m}$ 以内 ${ }^{[4]}$. 相应地, 沉水植物群落优势物种由海菜花 (Ottelia acuminata)、菼齿眼子菜 (Stuckenia pectinata) 和大茨藻 (Najas marina) 转变为耐污型的微齿眼子菜 (Potamogeton maackianus) 和金鱼藻 (Ceratophyllum demersum) 以及耐弱光的苦草 (Vallisneria natans) ${ }^{[4]}$.

沉水植物是湖泊生态系统重要的生产者和构建者, 其维持湖泊清水稳态的机制得到广泛的认可 ${ }^{[5-6]}$. 沉 水植物通过各种生物和非生物作用维持着湖泊的清水稳态, 例如增加水体自净能力 (吸附颗粒、抑制底泥再 悬浮), 为多种水生动物提供栖息地和食物, 增加生物多样性以及抑制浮游植物生长等 ${ }^{[7]}$. 洱海沉水植物群 落的退化对湖泊生态服务功能的发挥产生严重的负面效应, 例如, 在沉水植物衰退的过程中, 洱海面临着蓝

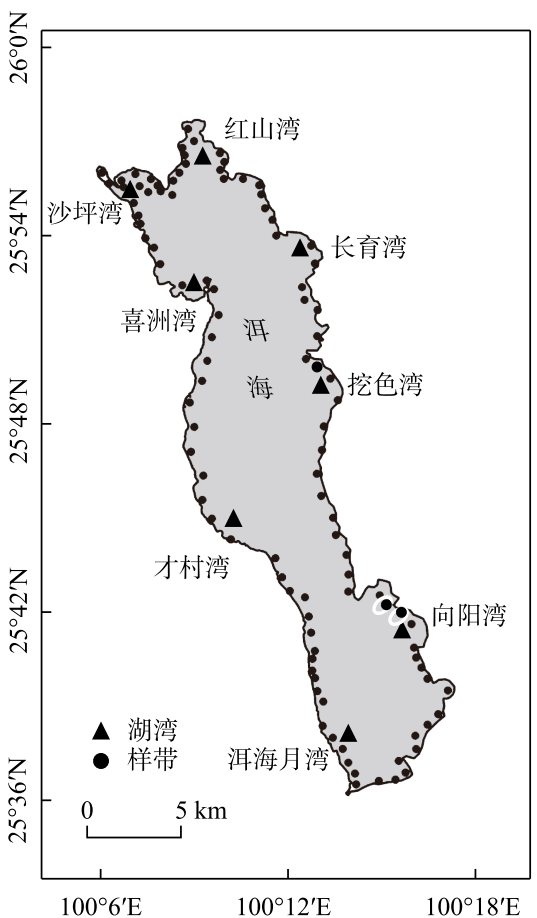

图 1 调查区域与样带布设示意图

Fig. 1 Schematic diagram of survey area and transection layout
藻水华的威胁, 自 1996 年暴发大面积蓝藻水华以来, 洱海又 先后在 1998、2003、2006、2009 和 2013 年暴发了大面积的蓝藻 水华,其他年份频发小面积水华现象 ${ }^{[8-9]}$. 在以往的水体生态 恢复实践中, 我们发现当沉水植物群落恢复至一定丰度和分 布面积时, 水体生态系统才可能处于相对稳定的理化状态或 清水稳态 ${ }^{[10-13]}$. 因此, 恢复沉水植被对于湖泊生态系统的健康 稳定及生态服务功能的发挥具有重要意义.

当前洱海处于富营养化初期, 其水生态系统具敏感性和 脆弱性, 洱海水生态系统仍可逆转, 是保护治理和生境改善的 关键时期 ${ }^{[14]}$. 因此, 为了解目前洱海沉水植被现状, 本研究对 洱海全湖沿岸带水生植被进行了详细的调查和分析, 以总结 洱海沉水植物群落遭受的威胁和面临的主要问题, 并通过对 比洱海典型退化湖湾一洱滨村水域沉水植被恢复与优化前后 沉水植物群落的组成差异, 探索洱海典型湖湾区沉水植被恢 复与群落优化模式, 为洱海后续生态恢复和优化管理方案的 制定提供科学的基础和指导, 也为我国其他类似湖泊的生态 修复提供借鉴和参考.

\section{1 研究方法}

\section{1 洱海沉水植物群落调查}

在 2016 年 7 月,对洱海全湖沿垂直于岸线方向随机布设 101 条植被调查样带, 样带之间间隔距离约为 $1 \mathrm{~km}$ (图 1), 每 条样带上以 $30 \sim 50 \mathrm{~m}$ 的距离随机设置采样点至植被分布边 界, 每个采样点处用镰式采草器 (采样面积 $0.2 \mathrm{~m}^{2}$ ) 随机采集 3 
个植物样方. 样方内的植物经洗净沥干水分, 按物种分拣, 现场鉴定物种类别后称取鲜重, 物种鉴定参考《中 国植物志 $\rangle^{[15]}$, 沉水植物优势物种的评判标准为物种鲜重占比大于群落鲜重的 $20 \%$. 沉水植物分布边界点 位由手持 GPS 定位系统 (Garmin GPSmap 60csx) 确定, 其标准为采集植物鲜重小于 $20 \mathrm{~g}$, 后由边界点位信息 和 ArcMap10.5 (Environment System Research Institute, ESRI) 软件计算全湖及主要湖湾沉水植被分布面积. 沉 水植物群落 Shannon-Wiener 多样性 (SW) 指数计算公式: $\mathrm{S} W=-\sum P_{i} \ln P_{i}$, 其中 $P_{i}=N_{i} / N, N_{i}$ 为物种 $i$ 的鲜重, $N$ 为样方群落中沉水植物总鲜重; 群落物种 Pielou 均匀度 $(P E)$ 指数计算公式: $P E=S W / H_{\text {max }}$, 其中 $H_{\text {max }}=$ $\ln S(S$ 为群落物种总数 $)$; 群落 Simpson 多样性指数计算公式: $D=1-\sum P_{i}^{2}\left(P_{i} \text { 含义同上 }\right)^{[16]}$.

\section{2 洱滨村水域沉水植物群落恢复与优化及本底与恢复调查}

洱滨村位于大理市下关镇, 地处洱海边, 该村农民收人主要以捕鱼业为主, 共有捕捞船只 116 艘, 渔业 年收人达 486 万元. 在洱海水质的富营养化进程不断加剧以及旅游业快速发展的大背景下, 洱滨村水域水 体生态系统遭受到严重的影响. 近期, 大理市政府在其湖滨带区域规划建设长约 $1 \mathrm{~km}$ 的湖滨生态绿道, 对 该区域水体生态服务功能提出较高要求. 因此,2019 年 9 月在该村水域(面积约 3.8 万 $\mathrm{m}^{2}$ ) 开展水生植被恢 复与群落优化研究 (图 2), 研究内容包括以下两大部分: (1) 细果野菱和金鱼藻的清除: 恢复种植前在水深 4 $\mathrm{m}$ 内的水域 (面积约 $31067 \mathrm{~m}^{2}$ ) 通过人工刈割 (水面下 $20 \sim 30 \mathrm{~cm}$ ) 和打捞的方式清除细果野菱和金鱼藻; (2) 沉水植物恢复与群落优化: 上述清除工作完成后, 采用无纺环保布袋粘土裹苗的方式在不同水深区间恢 复种植不同种类沉水植物种苗 (表 1). 粘土取自洱海附近人为干扰较少的荒山上, 土壤属于红土类型, 其化 学组成的质量百分比为: $\mathrm{Al}_{2} \mathrm{O}_{3}=10 \% \sim 13 \%, \mathrm{Fe}_{2} \mathrm{O}_{3}=6 \% \sim 8 \%, \mathrm{~N}=0.05 \% \sim 0.07 \%, \mathrm{P}=0.015 \% \sim 0.019 \%{ }^{[17]}$.

表 1 洱滨村水域不同水深区间沉水植物种苗恢复种植信息 “

Tab.1 Information on restoration of submerged macrophyte seedlings in areas of different water depths in Erbin Village

\begin{tabular}{|c|c|c|c|c|c|}
\hline $\begin{array}{c}\text { 水深/ } \\
\mathrm{m}\end{array}$ & $\begin{array}{c}\text { 面积/ } \\
\mathrm{m}^{2}\end{array}$ & 苦草 & 轮叶黑藻 & 穗状狐尾藻 & 光叶眼子菜 \\
\hline $0 \sim 2.5$ & 14714 & - & 株高 $30 \sim 50 \mathrm{~cm}, 50 \mathrm{~g} /$ 丛, 20 丛 $/ \mathrm{m}^{2}$ & 株高 $50 \sim 80 \mathrm{~cm}, 30$ 株 $/ \mathrm{m}^{2}$ & 株高 $70 \sim 100 \mathrm{~cm}, 20$ 株 $/ \mathrm{m}^{2}$ \\
\hline $2.5 \sim 4$ & 16353 & 株高 $30 \sim 50 \mathrm{~cm}, 60$ 株/ $\mathrm{m}^{2}$ & 株高 $30 \sim 50 \mathrm{~cm}, 50 \mathrm{~g} /$ 丛, 20 丛 $/ \mathrm{m}^{2}$ & 株高 $50 \sim 80 \mathrm{~cm}, 30$ 株 $/ \mathrm{m}^{2}$ & - \\
\hline $4 \sim 5$ & 7015 & 株高 $30 \sim 50 \mathrm{~cm}, 60$ 株 $/ \mathrm{m}^{2}$ & - & - & - \\
\hline
\end{tabular}

* “一”表示未实施恢复种植.

2019 年 7 月和 2020 年 6 月, 对洱滨村水域沉水植被分布区 (面积约 3.8 万 $\mathrm{m}^{2}$ ) 设置网格化固定采样点 105 个 (网格大小约为 $20 \mathrm{~m} \times 20 \mathrm{~m}$ ) (图 2), 各样点植物采集、鉴定和鲜重计算以及群落优势物种评判方法同 上,沉水植被分布边界点 (两边界点间隔距离约 $20 \sim 30 \mathrm{~m}$ ) 确定方法和分布面积计算方法同上.

\section{3 数据分析方法}

各项指标的均值比较采用单因素方差分析方法 (One-way ANOVA), 而洱滨村水域沉水植物群落及各项 指标恢复前后的差异采用配对样本 $T$ 检验方法进行比较. 在数据分析前, 对所有数据进行正态性和方差齐 性检验, 必要时对数据进行 $\log _{10}$ 转换以满足分析的假设条件. 采用 Microsoft Office 2019 和 SPSS 24.0 Software Package 进行图表制作和数据统计分析.

\section{2 研究结果}

\section{1 洱海沉水植物群落及其空间分布特征}

2016 年洱海沉水植物调查中, 共采集样方数量为 1879 个, 采集到 3 科 13 种沉水植物, 大部分物种属于 眼子菜科 (7 种), 某些历史物种 (如角果藻Z Zannichellia palustris 和海菜花Ottelia acuminata) 未见分布(表 2). 全湖植被分布面积仅为 $26.36 \mathrm{~km}^{2}$, 约占全湖面积的 $10.5 \%$. 洱海沿岸带沉水植物群落中, 全湖尺度上主要以 微齿眼子菜和金鱼藻占优势, 二者鲜重占比分别为 $40.9 \%$ 和 $22.8 \%$, 鲜重分别为 ( $1.39 \pm 0.08)$ 和 ( $0.78 \pm 0.06)$ $\mathrm{kg} / \mathrm{m}^{2}$ (图 3A).

在浅水区间 $(0 \sim 2.5 \mathrm{~m})$ 中, 累积调查样方数为 732 , 沉水植物群落鲜重为 $(3.73 \pm 0.13) \mathrm{kg} / \mathrm{m}^{2}$, 微齿眼子 


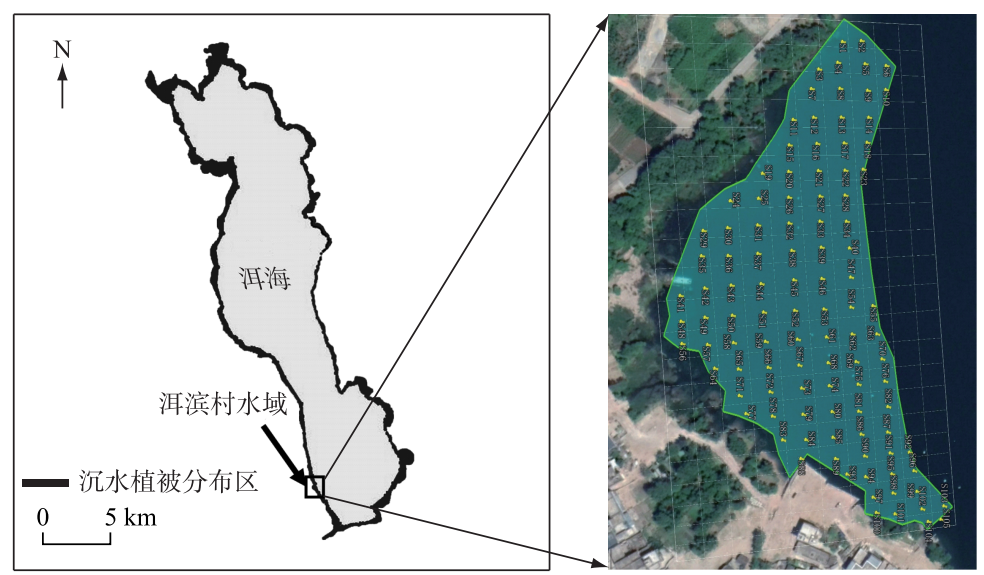

图 2 洱海洱滨村水域沉水植被恢复与优化研究示意图

Fig. 2 Schematic diagram of the study of submerged vegetation restoration and management in waters of Erbin Village in Lake Erhai

表 22016 年洱海沉水植物名录

Tab.2 List of submerged macrophytes of Lake Erhai in 2016

\begin{tabular}{lll}
\hline 科 Family & 属 Genus & 种 Species \\
\hline 金鱼藻科 Ceratophyllaceae & 金鱼藻属 Ceratophyllum & 金鱼藻 Ceratophyllum demersum \\
小二仙草科 Haloragaceae & 狐尾藻属 Myriophyllum & 穗状狐尾藻 Myriophyllun spicatum \\
& 苦草属 Vallisneria & 苦草 Vallisneria natans \\
& 黑藻属 Hydrilla & 轮叶黑藻 Hydrilla verticillata \\
& 茨藻属 Najas & 大茨藻 Najas marina \\
& 水车前属 Ottelia & 海菜花 Ottelia acuminata \\
& 眼子菜属 Potamogeton & 单果眼子菜 Potamogeton acutifolius \\
& & 微齿眼子菜 Potamogeton maackianus \\
& 荌齿眼子菜 Stuckenia pectinata \\
& 扭叶眼子菜 Potamogeton intortifolius \\
& 穿叶眼子菜 Potamogeton perfoliatus \\
& 光叶眼子菜 Potamogeton lucens \\
& 竹叶眼子菜 Potamogeton wrightii \\
\hline
\end{tabular}

菜鲜重占比较全湖稍有降低 $(P<0.05)$, 金鱼藻鲜重占比与全湖无显著差异 $(P>0.05)$, 二者鲜重占比分别为 $26.7 \%$ 和 $22.8 \%$. 此区间分布物种总数和样方平均物种数量均为最高, 分别为 13 和 $3.10 \pm 0.05(P<0.05)$ (图 3B).

中等水深区间 $(2.5 \sim 4 \mathrm{~m})$ 中, 累积调查样方数为 535 , 群落鲜重较浅水区域有明显增加 $(P<0.05)$, 达到 $(5.42 \pm 0.26) \mathrm{kg} / \mathrm{m}^{2}$, 物种总数减少 1 . 群落组成上依然是微齿眼子菜和金鱼藻占据优势, 微齿眼子菜鲜重占 比高达 $50.2 \%$, 金鱼藻鲜重占比约 $24.4 \%$, 二者鲜重分别为 $(2.74 \pm 0.21)$ 和 $(1.33 \pm 0.17) \mathrm{kg} / \mathrm{m}^{2}$ (图 $3 \mathrm{C}$ ).

$4 \mathrm{~m}$ 至沉水植被分布的边界区间内, 累积调查样方数为 612 , 群落鲜重显著小于浅水区和中等水深区 $(P<0.05)$, 仅为 $(1.25 \pm 0.10) \mathrm{kg} / \mathrm{m}^{2}$, 微齿眼子菜依然占据优势, 鲜重占比升高至 $54.9 \%(P<0.05)$; 而金鱼藻 鲜重则下降 $(P<0.05)$, 占比降至 $16.3 \%$; 苦草鲜重占比升高显著 $(P<0.05)$, 高达 $25.4 \%$. 三者鲜重分别为 $(0.69 \pm 0.08) 、(0.32 \pm 0.03)$ 和 $(0.206 \pm 0.04) \mathrm{kg} / \mathrm{m}^{2}$ (图 3D).

从洱海八大主要湖湾沉水植物群落构成来看, 微齿眼子菜在大部分湖湾占据优势, 金鱼藻在才村湾和 

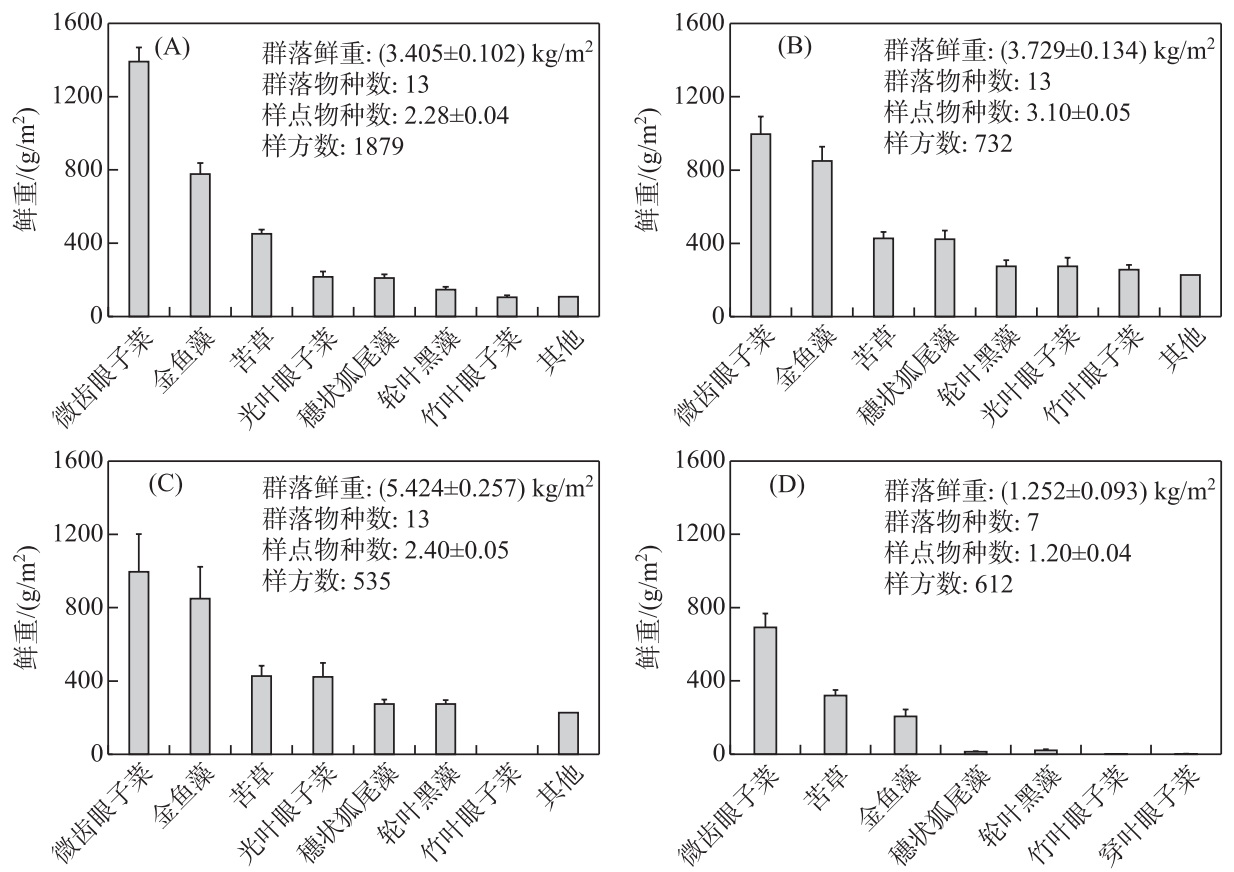

图 32016 年 7 月洱海不同水深区间沉水植物群落及物种鲜重 ( A: 全湖;B:0 2.5 m;C:2.5 4 m;D : >4 m)

Fig. 3 The fresh weight of submerged macrophyte community and each species in different water depth areas of Lake Erhai in July 2016 ( A: whole lake; B: 0-2.5 m; C: 2.5-4 m; D: >4 m)

沙坪湾占优势, 二者在除东侧的向阳湾和长育湾的其他湖湾中的鲜重占比从 $73.9 \% \sim 89.8 \%$ 不等, 在向阳湾 和长育湾鲜重占比分别为 $34.3 \%$ 和 $53.4 \%$ (表 3). 八大湖湾中沉水植物群落物种数范围为 $5 \sim 11$, 其中才村 湾、挖色湾、洱海月湾和长育湾较少, 分别为 $5 、 6 、 7$ 和 7 . 八大湖湾沉水植物群落鲜重范围为 $(2.356 \pm 1.282) \sim$ $(5.424 \pm 1.091) \mathrm{kg} / \mathrm{m}^{2}$, 样方 $\left(0.2 \mathrm{~m}^{2}\right)$ 物种数范围为 $(1.6 \pm 0.1) \sim(2.81 \pm 0.2)$, Shannon-Wiener 指数、Pielou 均 匀度指数以及 Simpson 指数范围分别为 $0.23 \sim 0.73 、 0.25 \sim 0.69$ 和 $0.16 \sim 0.45$ (表 3). 浮叶植物细果野菱 (Trapa maximowiezii) 主要分布在八大主要湖湾的浅水区 $\left(2.5 \mathrm{~m}\right.$ 内), 平均鲜重约为 $(1.734 \pm 0.244) \mathrm{kg} / \mathrm{m}^{2}$, 均 高于其他沉水植物鲜重, 为该区域沉水植物群落鲜重的 $37.4 \%$ (表 2), 该区域中样方物种数接近所有湖湾的 最高值, 但是其他群落指数均居于中等水平 (表 3). 此外, 调查还发现洱海北部红山湾和沙坪湾的局部浅水 水域中满江红 (Azolla imbricata) 等过度生长以及湖湾沼泽化严重等现象 (图 4).

\section{2 洱滨村水域沉水植物恢复与优化成效}

洱滨村水域沉水植物群落结构在工程实施后发生显著改变, 群落鲜重、样方物种数、Shannon-Wiener 指 数、Pielou 均匀度指数以及 Simpson 指数显著高于恢复前 $(P<0.05$, 表 4), 增幅分别为 $18.8 \% 、 40.1 \% 、 67.2 \%$ 、 $35.4 \%$ 和 $61.8 \%$, 恢复物种穗状狐尾藻、轮叶黑藻及苦草鲜重增幅分别高达 $130.1 \%$ 、247.5\% 和 $55.9 \%(P<$ 0.05 , 表 4). 细果野菱由恢复前的 $(0.807 \pm 0.137) \mathrm{kg} / \mathrm{m}^{2}$ 下降至恢复后的 $(0.040 \pm 0.009) \mathrm{kg} / \mathrm{m}^{2}(P<0.001)$, 降 幅高达 $95.0 \%$,金鱼藻鲜重则由 $(2.623 \pm 0.266) \mathrm{kg} / \mathrm{m}^{2}$ 下降至 $(1.248 \pm 0.114) \mathrm{kg} / \mathrm{m}^{2}(P<0.001)$, 降幅达 $52.4 \%$. 同时群落物种数由 10 增加到 12 , 增加了小眼子菜 (Potamogeton pusillus) 和大茨藻 (Najas marina) (表 4). 此 外,沉水植被分布面积由恢复前的 $38082 \mathrm{~m}^{2}$ 增加至 $42230 \mathrm{~m}^{2}$, 增幅约 $10.9 \%$, 且分布最深处的植物主要为恢 复种植的无纺环保布袋包裹的苦草种苗. 恢复实施后, 沉水植物群落在各水深区间各项群落和物种指标改 善显著,尤其是浅水区和中等水深区 (表 4$)$. 


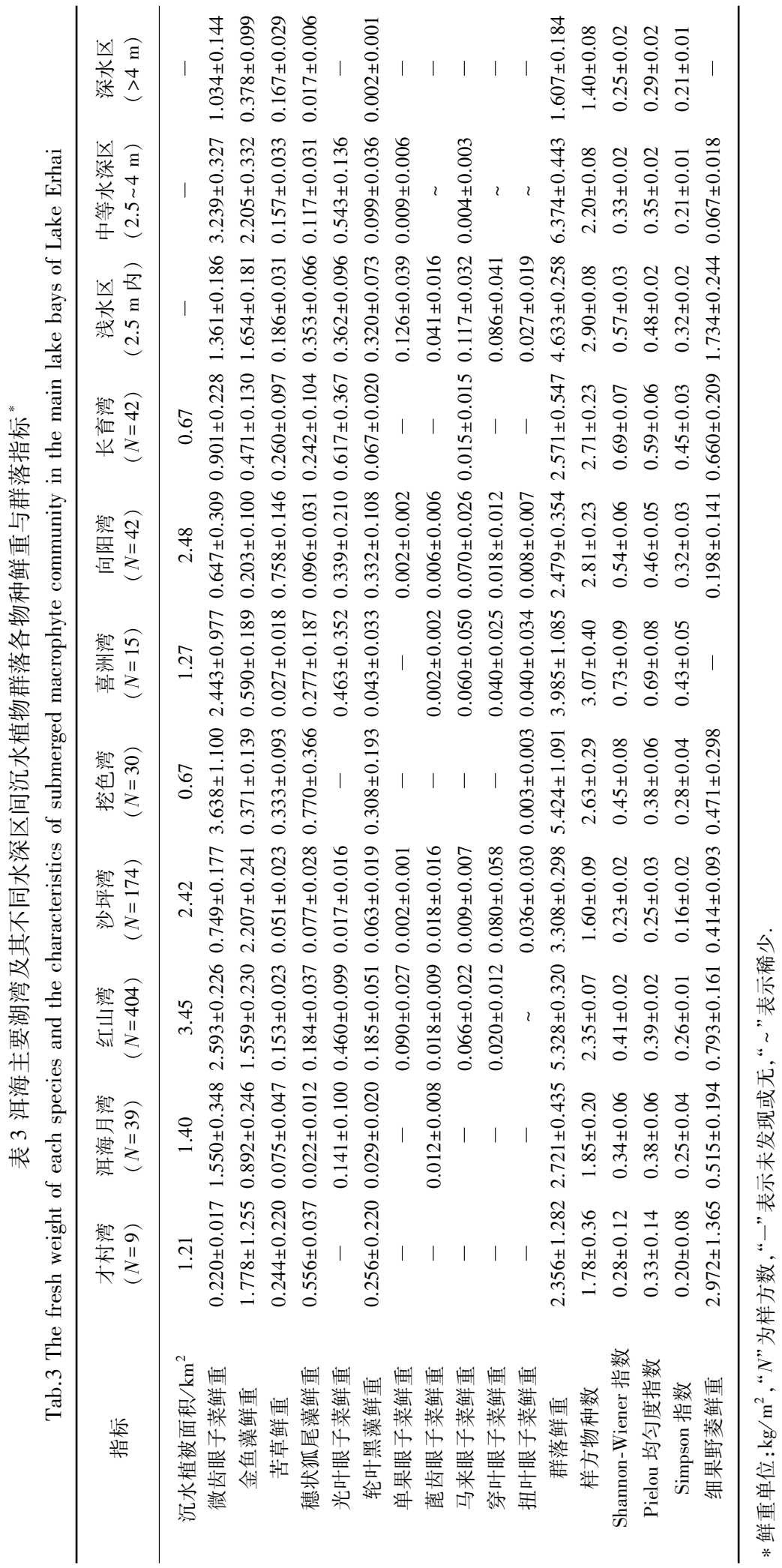



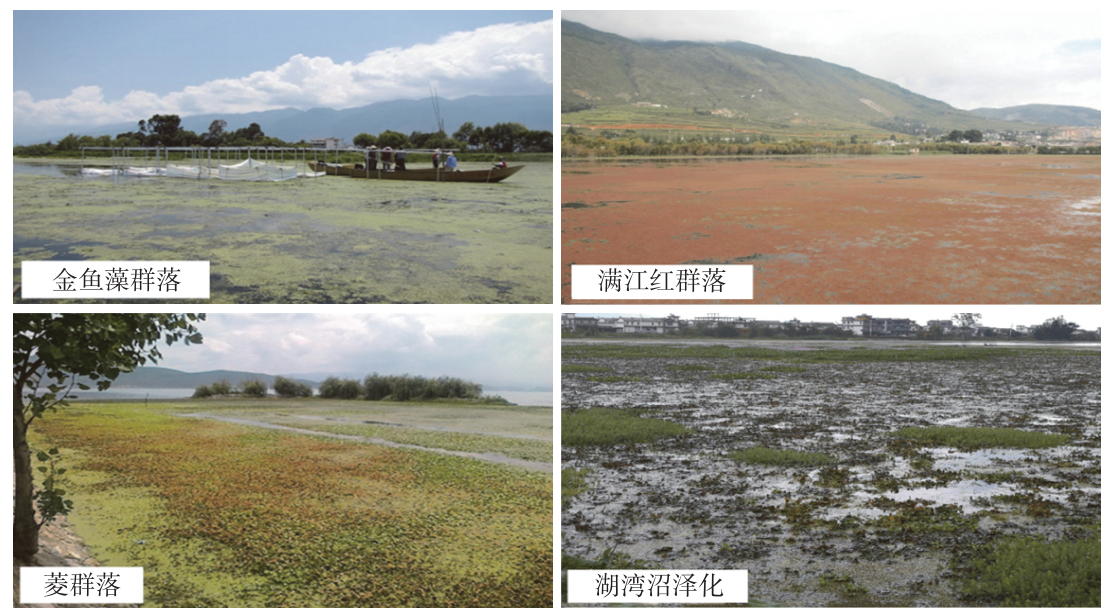

图 4 洱海湖湾水生植物沼泽化趋势

Fig.4 Swamping trend of aquatic plants in bays of Lake Erhai

\section{3 讨论与结论}

近 50 年来, 流域人湖营养盐不断增加、水质持续下降以及藻类生物量逐年升高驱动着洱海沉水植被的 快速演替, 同时水位的大幅波动加速了洱海水生态系统由清向浊的转变, 并导致沉水植被退化和特有物种 消失 ${ }^{[3]}$. 本研究中调查显示的洱海沉水植物分布面积及主要优势物种与符辉等 ${ }^{\left[{ }^{3}\right]}$ 调查统计的相似, 优势物 种均为微齿眼子菜、金鱼藻及苦草, 表明洱海沉水植被目前仍然处于退化阶段, 无明显改善趋势. 此外, 洱海 湖区沉水植物种子库资源稀少且萌发率极低, 若不加强管理与补充, 将对洱海沉水植被的恢复与洱海水生 态系统的良性循环造成严重的不利影响 ${ }^{[3]}$.

本研究调查显示洱海沉水植物群落物种数量较 2011 年减少约 13 种 ${ }^{[2]}$, 分布面积占全湖水面面积的占 比较 $1980 \mathrm{~s}$ 下降超过 $70 \%{ }^{[3]}$. 调查总结洱海沉水植被面临的主要问题为: 1 ) 主要湖湾浅水区遭受浮叶植物 细果野菱过度生长的威胁;2) 中等水深区面临微齿眼子菜和金鱼藻的过度生长导致的群落结构的单一化; 3) 深水区面临着面积萎缩的风险. 洱海沉水植物群落在 $2.5 \mathrm{~m}$ 以内的浅水生境主要面临着浮叶植物 (细果 野菱) 大量生长的胁迫. 菱属植物是富营养水体常见类群之一 ${ }^{[18]}$, 其常在水面形成致密的冠层, 对光照产生 严重遮蔽效应 ${ }^{[19]}$, 抑制沉水植物生长 ${ }^{[20]}$, 秋、冬季死亡后又形成内源性营养负荷, 导致系统富营养化加剧并 威胁系统的生态平衡 ${ }^{[21]}$. 同时, 洱海沉水植物群落自身也面临结构组成退化的威胁. 全湖主要湖湾中沉水 植物群落物种数较少且结构简单, 群落物种多样性和均匀度均较低. 金鱼藻和微齿眼子菜由于其强大的生 长力, 在洱海大部分湖湾常常形成单优群落或二者的共优群落 ${ }^{[22]}$, 其过度生长导致群落物种数和生物多样 性大幅下降, 从而削弱群落稳定性. 二者在群落中形成竞争优势的机理有所差异, 微齿眼子菜是中富营养化 水体常见的多年生冠层型物种 ${ }^{[23]}$, 对光的适应范围广 ${ }^{[24]}$, 而金鱼藻是非根生沉水植物, 能够适应比较广的 营养浓度范围, 其在夏季快速繁殖, 抑制其他物种的生长 ${ }^{[25]}$. 二者对浅水区沉水植物群落的结构和功能起 着决定性作用, 在富营养化湖泊中常常造成群落结构的简单和不稳定. 此外, 金鱼藻年内生物量波动较大, 在秋季衰退 ${ }^{[26]}$ 后, 导致群落结构和组成剧烈波动, 从而削弱了群落的生态功能 ${ }^{[27-28]}$. 相关研究表明, 富营养 化水体中保持金鱼藻较低的覆盖度是合理的 ${ }^{[29]}$. 微齿眼子菜虽占据大部分优势, 但由于其生物量相对稳 定 ${ }^{[25]}$ 且在洱滨村水域丰度较低, 本研究暂未考虑对其进行收割管理. 因此, 在以追求改善水质和系统稳定 为目标的洱海中, 必须对沉水植物群落采取一定的恢复和优化管理措施, 降低浮叶植物细果野菱丰度以改 善沉水植物群落的生境, 同时适度降低金鱼藻和微齿眼子菜丰度以及增加其他物种丰度以改善沉水植物群 落结构, 扩大其清水稳态效应. 


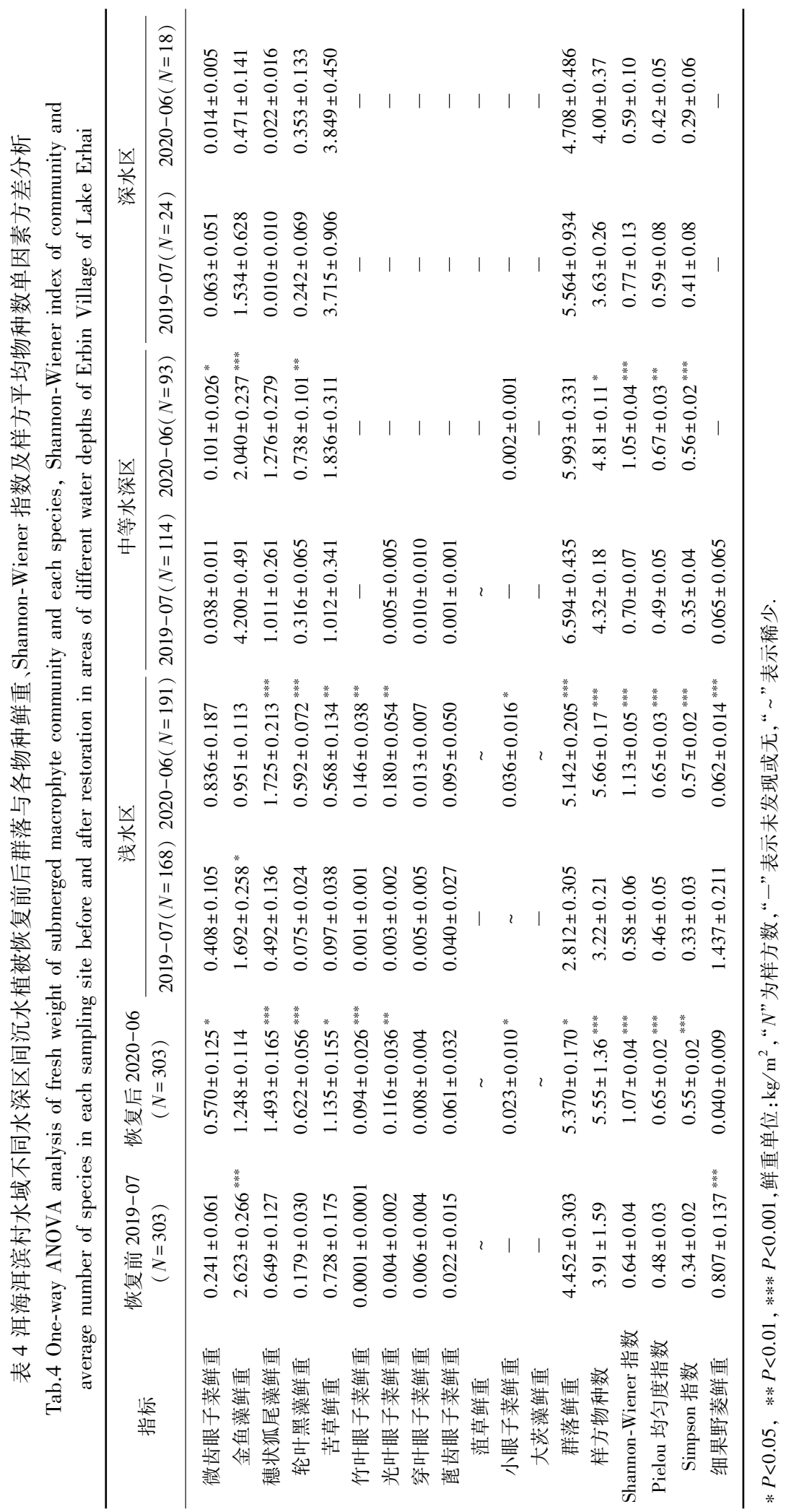


关于沉水植物生境改善措施已有诸多研究和实践, 主要分为物理、化学和生物三类 ${ }^{[30]}$, 其中物理收割是 为各地管理者们普遍认可的对降低湖泊营养盐、提高水生植物群落多样性及治理沼泽化的有效措施 ${ }^{[31-32]}$, 具有环境友好和副作用小等特点 ${ }^{[33-34]}$. 物理收割致密的浮叶植物细果野菱与冠层型沉水植物金鱼藻一方面 为水体底部的机会物种提供了生态位, 同时也为下层的沉水植物繁殖体、萌芽及休眠体带来了充足的光照 和溶解氧, 有利于群落生物多样性的提高 ${ }^{[35-36]}$. 人工收割的同时, 由于洱海沉水植物群落中沉水植物种子库 退化或缺失 ${ }^{[25]}$, 还需要进行沉水植物种苗的移栽补充, 提高群落中的物种丰富度以及促进沉水植物的分布 面积扩增. 二者必须结合实施, 才能有效提高沉水植物的丰富度, 促进沉水植被生境的改善和群落的优化, 有助于实现洱海水体生态系统的健康稳定状态.

“十二五” 国家水专项洱海研究课题指出当前洱海处于富营养化初期, 其水生态系统具敏感性和脆弱 性, 但洱海水生态系统仍可逆转, 是保护治理和生境改善的关键时期 ${ }^{[14]}$. 本研究是基于以上研究成果的积 累而开展的实践研究. 在洱滨村水域沉水植物恢复与优化的具体实践中, 选择洱海中除微齿眼子菜和金鱼 藻以外相对丰度较高 (在洱滨村水域相对丰度也较高) 的轮叶黑藻、苦草、穗状狐尾藻和光叶眼子菜作为目 标恢复物种, 因为四者在 $4 \mathrm{~m}$ 内水域均能稳定存活且可相互共生形成复合群落 ${ }^{[37]}$. 其中苦草在洱海大于 4 $\mathrm{m}$ 的深水区优势度仅次于微齿眼子菜, 但其较微齿眼子菜能耐受更低的水下光照 ${ }^{[38]}$, 可优先选择其作为深 水区扩增的目标物种. 此前研究表明, 洱海本地的红壤在促进沉水植物恢复中具有良好的效果 ${ }^{[39-40]}$, 且天然 廉价, 因此本研究选择其作为辅助沉水植物定植的材料, 另外采用可降解的无纺环保布袋包裹, 使种苗在恢 复生长初期有稳定的底质条件以达到良好的恢复效果.

对比洱滨村水域沉水植被恢复与管理研究前后沉水植物群落调查结果表明, 洱滨村水域沉水植物群落 结构得到明显改善, 群落各项物种多样性指数和均匀度指数显著提升且沉水植被分布面积增加明显; 细果 野菱和金鱼藻优势度在工程水域有显著下降,浅水区沉水植物生境得到持续改善, 恢复物种苦草和轮叶黑 藻鲜重在工程水域得到大幅提升, 阶段性恢复成效显著. 本研究在 9 月份对细果野菱和金鱼藻进行控制, 明 显抑制了其年内的有性生殖和下一年度的生长优势, 同时原有的植物与补充的种苗得到了更多的生长空 间, 这使第二年的沉水植物群落结构得到了明显的改善. 同时, 虽然处于生长后期, 但在本来种子库贫乏的 深水区投放的大量耐弱光的苦草种苗依然存活并扩增, 说明恢复措施具有良好的辅助苦草定植生长的作用.

由于本研究时间较短, 无法充分显示恢复管理措施的长期效应, 因此需要在后期进行长时间尺度的跟 踪监测, 对恢复效果进行充分评价. 洱海沉水植被多分布于本研究中的八大主要湖湾中, 多为退化型湖湾, 洱滨村水域水生植被的恢复成效对于这些湖湾的沉水植被恢复具有重要的指导意义. 洱海沉水植被的丰度 和覆盖度的提升有助于提高系统内食物网复杂度和生物多样性, 从而增强生态系统的稳定性和抵抗力, 最 终增强洱海生态系统的生态服务功能. 此外, 洱海沉水植被恢复与管理所取得的成效和积累的经验可为我 国其他类似湖泊的生态恢复提供有价值的参考和借鉴.

综上,通过对比分析洱海沉水植被现状以及洱滨村水域沉水植被恢复与优化研究的阶段性成效,我们 总结得出: 1 ) 目前洱海具备了在部分湖湾恢复沉水植被的水环境条件; 2 洱海典型湖湾沉水植被恢复可参 考的基本模式: 在 $0 \sim 2.5 \mathrm{~m}$ 的浅水区域对金鱼藻和细果野菱进行打捞清除, 抑制其优势, 而后在 $6 \mathrm{~m}$ 以内水 域 (洱海沉水植物分布水深范围) 按照适生水深补种苦草、轮叶黑藻、竹叶眼子菜、光叶眼子菜及穗状狐尾藻 等物种进行群落的恢复与优化, 在后期可组织加强湖面清理巩固效果, 并加强跟踪监测; 3 ) 洱滨村水域的恢 复成效可以为洱海其他类似富营养湖湾沉水植被的恢复提供可靠的经验和科学指导; 具体实施中,应结合 具体湖湾的具体情况对恢复管理方案作相应的优化调整.

\section{4 参考文献}

[ 1 ] Huang HJ, Wang YP, Li QH. Climatic characteristics over Lake Erhai basin in the late 50 years and the impact on water resources of Lake Erhai. Meteorological Monthly, 2013, 39(4): 436-442. [黄慧君, 王永平, 李庆红. 洱海流域近 50 年气候变化特征及其对洱海水资源的影响. 气象, 2013, 39(4): 436-442.]

[ 2 ] Li EH, Wang XL, Cai XB et al. Features of aquatic vegetation and the influence factors in Erhai Lake shore wetland. $J$ Lake Sci, 2011, 23(5) : 738-746. DOI: 10.18307/2011.0511. [厉恩华, 王学雷, 蔡晓斌等. 洱海湖滨带植被特征及 其影响因素分析. 湖泊科学, 2011, 23(5): 738-746.] 
[ 3 ] Fu H, Yuan GX, Cao T et al. Succession of submerged macrophyte communities in relation to environmental change in Lake Erhai over the past 50 years. J Lake Sci, 2013, 25(6) : 854-861. DOI: 10.18307/2013.0609. [符辉, 袁桂香, 曹 特等. 洱海近 50a 来沉水植被演替及其主要驱动要素. 湖泊科学, 2013, 25(6):854-861.]

[ 4 ] Dai QY. A preliminary study of the aquatic vegetation in erhaihu lake. Transactions of Oceanology and Limnology, 1984, (4) : 31-41. [戴全裕. 洱海水生植被的初步研究. 海洋湖沼通报, 1984, (4) : 31-41.]

[ 5 ] Gao HL, Qian X, Wu HF et al. Combined effects of submerged macrophytes and aquatic animals on the restoration of a eutrophic water body-A case study of Gonghu Bay, Lake Taihu. Ecological Engineering, 2017, 102: 15-23. DOI: 10. 1016/j. ecoleng.2017.01.013.

[6] Phillips G, Willby N, Moss B. Submerged macrophyte decline in shallow lakes: What have we learnt in the last forty years? Aquatic Botany, 2016, 135: 37-45. DOI: 10.1016/j.aquabot.2016.04.004.

[ 7 ] Jeppesen E, Søndergaard M, Søndergaard M et al eds. The structuring role of submerged macrophytes in lakes. New York: Springer, 1998. DOI: 10.1007/978-1-4612-0695-8.

[ 8 ] Chen JL, Hu MM, Zhou HD et al. Studies on population dynamics and the underlying impact factors of phytoplankton during the cyanobacteria bloom in lake Erhai. Acta Hydrobiologica Sinica, 2015, 39(1) : 24-28. DOI: 10.7541/2015.3. [陈 建良, 胡明明, 周怀东等. 洱海蓝藻水华暴发期浮游植物群落变化及影响因素. 水生生物学报, 2015, 39(1): 24-28.]

[ 9 ] Zhu R, Wang H, Yu DZ et al. Dynamic changes of microcystins and phytoplankton during the cyanobacterial bloom in Lake Erhai in 2013. J Lake Sci, 2015, 27(3) : 378-384. DOI: 10.18307/2015.0302. [朱荣, 王欢, 余得昭等. 2013 年 洱海水华期间微囊藻毒素和浮游植物动态变化. 湖泊科学, 2015, 27(3) : 378-384.]

[10] Zeng L, He F, Dai ZG et al. Effect of submerged macrophyte restoration on improving aquatic ecosystem in a subtropical, shallow lake. Ecological Engineering, 2017, 106: 578-587. DOI: 10.1016/j.ecoleng.2017.05.018.

[11] Søndergaard M, Johansson LS, Lauridsen TL et al. Submerged macrophytes as indicators of the ecological quality of lakes. Freshwater Biology, 2010, 55(4) : 893-908. DOI: 10.1111/j.1365-2427.2009.02331.x.

[12] Grzywna A, Sender J, Bronowicka-Mielniczuk U. Physical and chemical variables, species composition and coverage of macrophytes in ponds (case study in eastern Poland). Applied Ecology and Environmental Research, 2018, 16(3) : 21292139. DOI: $10.15666 /$ aeer/1603_21292139.

[13] Liu H, Zhou W, Li XW et al. How many submerged macrophyte species are needed to improve water clarity and quality in Yangtze floodplain lakes? Science of the Total Environment, 2020, 724: 138267. DOI: 10.1016/j.scitotenv.2020.138267.

[14] National Science and Technology Achievement Network. Conversion project I Integrated improvement technology system for lake degraded habitats in the early stages of eutrophication.https://www. sohu.com/a/340823696_806167, 2019-9-14. [国家科技成果网. 转化项目I富营养化初期湖泊退化生境综合改善技术体系. ]

[15] Editorial Board of Flora of China ed. Flora of China. Beijing: Science Press, 1993. [《中国植物志》编辑委员会. 中国植 物志. 北京: 科学出版社, 1993.]

[16] Yuan CB, Bai XH, Zhu TS et al. Long-term effects of the harvesting of Trapa natans on local water quality and aquatic macrophyte community in Lake Erhai, China. Frontiers in Environmental Science, 2021, 9. DOI: 10. 3389/fenvs. 2021.706746.

[17] Zhu LD, Zhou SZ, Feng-Quan LI et al. Geochemical behavior of major elements of Pleistocene red earth in South China. Geochimica, 2007, 36: 295-302.

[18] Yan ZS, Chen MD, Li FY et al. Effects on the restoration of eutrophic water by large-scale cultivation of water caltrop. Science Technology and Engineering, 2016, 16(9): 103-108. [闻子胜, 陈敏东, 李凤英等. 大面积种植红菱对富营养 化水体修复效果的影响. 科学技术与工程, 2016, 16(9): 103-108.]

[19] Klančnik K, Iskra I, Gradinjan D et al. The quality and quantity of light in the water column are altered by the optical properties of natant plant species. Hydrobiologia, 2018, 812(1) : 203-212. DOI: 10.1007/s10750-017-3148-9.

[20] Barko JW, Smart RM. Comparative influences of light and temperature on the growth and metabolism of selected submersed freshwater macrophytes. Ecological Monographs, 1981, 51(2) : 219-236. DOI: 10.2307/2937264.

[21] Kato Y, Nishihiro J, Yoshida T. Floating-leaved macrophyte (Trapa japonica) drastically changes seasonal dynamics of a temperate lake ecosystem. Ecological Research, 2016, 31(5) : 695-707. DOI: 10.1007/s11284-016-1378-3.

[22] Ni LY. Growth of Potamogeton maackianus under low-light stress in eutrophic water. Journal of Freshwater Ecology, 2001, 
16(2) : 249-256. DOI: $10.1080 / 02705060.2001 .9663809$.

[23] Wang XM, Sun SG, Guo YH. A primary study of germination characteristic of Potamogeton maackianus. Acta Hydrobiologica Sinica, 2003, 27 (1) : 95-97. [王孝民, 孙士国, 郭友好. 微齿眼子菜瘦果萌发特性的初步研究. 水生生物学 报, 2003, 27(1): 95-97.]

[24] Song X, Cao T, Zhu GR et al. Adaptive comparison of Potamogeton maackianus and p.malaianus to various water depths in an experimental study. Resources and Environment in the Yangtze Basin, 2014, 23(8): 1081-1089. [宋金鍂, 曹特, 祝国 荣等. 微齿眼子菜与马来眼子菜对水深变化的适应性比较研究. 长江流域资源与环境, 2014, 23(8): 1081-1089.]

[25] He L, Zhu TS, Cao T et al. Characteristics of early eutrophication encoded in submerged vegetation beyond water quality: A case study in Lake Erhai, China. Environmental Earth Sciences, 2015, 74(5) : 3701-3708. DOI: 10.1007/s12665015-4202-4.

[26] Dong J, Chang MY, Li CL et al. Allelopathic effects and potential active substances of Ceratophyllum demersum L. on Chlorella vulgaris Beij. Aquatic Ecology, 2019, 53(4) : 651-663. DOI: 10.1007/s10452-019-09715-2.

[27] Moore TP, Clearwater SJ, Duggan IC et al. Invasive macrophytes induce context-specific effects on oxygen, pH, and temperature in a hydropeaking reservoir. River Research and Applications, 2020, 36( 8) : 1717-1729. DOI: 10.1002/rra.3674.

[28] Sayer CD, Davidson TA, Jones JI. Seasonal dynamics of macrophytes and phytoplankton in shallow lakes: A eutrophication-driven pathway from plants to plankton? Freshwater Biology, 2010, 55(3) : 500-513. DOI: 10.1111/j.1365-2427. 2009.02365.x.

[29] Dai YR, Jia CR, Liang W et al. Effects of the submerged macrophyte Ceratophyllum demersum L. on restoration of a eutrophic waterbody and its optimal coverage. Ecological Engineering, 2012, 40: 113-116. DOI: 10.1016/j. ecoleng.2011. 12.023 .

[30] Madsen JD, Adams MS, Ruffier P. Harvest as a control for sago pondweed (Potamogeton pectinatus L.) in Badfish Creek, Wisconsin: Frequency, efficiency and its impact on stream community oxygen metabolism. Journal of Aquatic Plant Management, 1988, 26: 20-25.

[31] Evans JM, Wilkie AC. Life cycle assessment of nutrient remediation and bioenergy production potential from the harvest of Hydrilla (Hydrilla verticillata). Journal of Environmental Management, 2010, 91(12) : 2626-2631. DOI: 10.1016/j.jenvman.2010.07.040.

[32] Liu PP, Bai JH, Zhao QQ et al. A review on terrestrialization and primary productivity of aquatic vegetations in lake ecosystems. Wetland Science, 2013, 11(3) : 392-397. [刘佩佩, 白军红, 赵庆庆等. 湖泊沼泽化与水生植物初级生产力 研究进展. 湿地科学, 2013, 11(3): 392-397.]

[33] Richardson RJ. Aquatic plant management and the impact of emerging herbicide resistance issues. Weed Technology, 2008, 22 (1) : 8-15. DOI: $10.1614 /$ wt-07-034.1.

[34] Ban S, Toda T, Koyama M et al. Modern lake ecosystem management by sustainable harvesting and effective utilization of aquatic macrophytes. Limnology, 2019, 20(1) : 93-100. DOI: 10.1007/s10201-018-0557-z.

[35] Best EPH. The impact of mechanical harvesting regimes on the aquatic and shore vegetation in water courses of agricultural areas of the Netherlands. Vegetatio, 1994, 112(1) : 57-71. DOI : 10.1007/BF00045100.

[36] Xu WW, Hu WP, Deng JC et al. Effects of harvest management of Trapa bispinosa on an aquatic macrophyte community and water quality in a eutrophic lake. Ecological Engineering, 2014, 64: 120-129. DOI: 10.1016/j.ecoleng.2013.12.028.

[37] Ye BB, Chu ZS, Wu AP et al. Optimum water depth ranges of dominant submersed macrophytes in a natural freshwater lake. PLoS One, 2018, 13(3) : e0193176. DOI: 10.1371/journal.pone.0193176.

[38] Chen JF, Cao T, Zhang XL et al. Differential photosynthetic and morphological adaptations to low light affect depth distribution of two submersed macrophytes in lakes. Scientific Reports, 2016, 6: 34028. DOI: 10.1038/srep34028.

[39] Zhu TS, Cao T, Ni LY et al. Improvement of water quality by sediment capping and re-vegetation with Vallisneria natans L. : A short-term investigation using an in situ enclosure experiment in Lake Erhai, China. Ecological Engineering, 2016, 86: 113-119. DOI: 10.1016/j.ecoleng.2015.10.031.

[40] Chen XX, Tang X, Chou QC et al. Effects of red soil-modified sediment on water quality and submerged macrophytes: An in situ experiment in Erhai Lake. Journal of Hydroecology, 2020, 41(3) : 51-56. DOI: 10.15928/j.1674-3075.2020.03. 007. [陈晓希, 汤金金, 丑庆川等. 洱海底泥红壤改性对水质和水生植物的影响. 水生态学杂志, 2020, 41 (3) : 51-56.] 